\title{
THE EFFECT OF REMIFENTANIL ON INTUBATION CONDITIONS IN PATIENTS UNDERGOING CESAREAN DELIVERY UNDER GENERAL ANESTHESIA: COMPARISON OF TWO DOSING REGIMENS
}

\author{
Marija S. Kutlešićc ${ }^{1,2}$, Ranko M. Kutlešić ${ }^{2,3}$, Tatjana Ilić-Mostić ${ }^{4,5}$, Danka Mostić Stanišić ${ }^{6}$ \\ ${ }^{1}$ Clinic of Anesthesiology, University Clinical Centre Niš, Niš, Serbia \\ ${ }^{2}$ Clinic of Gynecology and Obstetrics, Clinical Centre Niš, Niš, Serbia \\ ${ }^{3}$ Faculty of Medicine, University of Niš, Niš, Serbia \\ ${ }^{4}$ Institute of Gynecology and Obstetrics, Department of Anesthesiology, Clinical Center of Serbia, Belgrade, Serbia \\ ${ }^{5}$ Faculty of Medicine, University of Belgrade, Belgrade, Serbia \\ ${ }^{6}$ Institute of Obstetrics and Gynecology, Clinical Center of Serbia, Belgrade, Serbia
}

\begin{abstract}
The objective of our study was to compare the effects of two remifentanil dosing regimens, used during induction-delivery period of cesarean section, and of remifentanil-free control on maternal intubating conditions and hemodynamic response to endotracheal intubation as well as on neonatal outcome. Seventy seven ASA physical status I-II women with singleton term pregnancy, who were scheduled for elective cesarean section in general anesthesia and have given written informed consent, were enrolled in this prospective, randomized controlled study and divided in three groups: A - 31 patient received $1 \mu \mathrm{g} / \mathrm{kg}$ remifentanil bolus before the induction of anesthesia, followed by $0.15 \mu \mathrm{g} / \mathrm{kg} / \mathrm{min}$ remifentanil infusion that was stopped after the skin incision; $B-27$ patients received only $1 \mu \mathrm{g} / \mathrm{kg}$ remifentanil bolus; $C-19$ patients did not receive remifentanil until the delivery of the baby. Intubating conditions were qualified as excellent, good or poor. Group A had significantly higher number of patients with excellent intubating conditions $(p=0.011)$; majority of patients with good intubating conditions were in group $C(p=0.017)$. Systolic, diastolic, main arterial pressure and heart rate raised significantly in group $C$ compared to $A$ and $B$ $(p<0.001)$. Neonatal outcome did not differ between groups - all neonates were vital with first minute Apgar scores $\geq 8$. In conclusion, our dosing regimen of remifentanil $1 \mu \mathrm{g} / \mathrm{kg}$ bolus given immediately before the induction followed by $0.15 \mu \mathrm{g} / \mathrm{kg} / \mathrm{min}$ interrupted after skin incision provided the best compromise between the achievement of excellent intubating conditions, attenuation of maternal hemodynamic stress response to endotracheal intubation and avoidance of neonatal respiratory depression.
\end{abstract}

Key words: anesthesia, obstetrical, endotracheal intubation, remifentanil.

\section{Introduction}

The time interval from induction to anesthesia to the delivery of the baby (induction-delivery, I-D interval) during caesarean section performed under general anesthesia (GA) represents very vulnerable period concerning both maternal and fetal/neonatal wellbeing. All medications that the mother receives (except muscle relaxants) will cross uteroplacental membrane and affect the fetus directly (hearth and respiratory rate, muscle tone) and indirectly (by influencing maternal hemodynamics, uteroplacental perfusion, uterine tone) [1-3]. This is the reason why the doses of anesthetics are traditionally reduced as much as possible, which could lead to light anesthesia with increased risk of maternal intraoperative awareness (reported incidence of $0.2-0.9 \%$ ) $[4,5]$ and exaggerated

Correspondence to: Marija S. Kutlešić, MD, Ph.D.

Clinic of Gynecology and Obstetrics, Clinical Centre Niš, Zetska Str., 18000 Niš, Serbia

E-mail: mkutlesic5@gmail.com

Phone: +381642302 324, fax: +381 184224063

Received June $2^{\text {nd }}, 2018$, Accepted June $11^{\text {th }}, 2018$ neuroendocrine stress response to laryngoscopy, endotracheal intubation and surgical stimuli. Mechanical stimulation of pharyngeal and laryngeal proprioceptors during direct laryngoscopy, endotracheal intubation and cuff inflation activates hypothalamo-pituitary-adrenal axis, with subsequent increase in hearth rate (up to 20\%), blood pressure (40-50\%), capillary wedge, intracranial and intraocular pressure, possibly leading to severe cardio- and cerebrovascular complications [6-9]. Increasing number of vulnerable patients in obstetrics population nowadays makes this problem more and more serious. We can expect much more parturients with high-risk pregnancies, advanced age, morbid obesity and complex comorbidities and, consequently, much more need for some drug that could help us blunting the unwanted effects of endotracheal intubation $[9,10]$.

Among different pharmacological options used to attenuate hemodynamic response to endotracheal intubation and surgical incision (direct vasodilatators, $\beta$ blockers, calcium channel blockers, $\alpha_{2}$ agonists, anticonvulsant drugs such as gabapentin, magnesium, local anesthetics) opioids are still the most extensively used 
$[11,12]$. It seems that remifentanil, ultra-short acting synthetic opioid, due to its specific pharmacokinetics, could be the appropriate drug to use during I-D interval, where a brief but intense analgesia without prolonged effect is desirable [13-18].

Remifentanil has a rapid onset of action (1-1.5 min), rapid redistribution and context sensitive half time 3-5 min; its metabolism depends on nonspecific tissue and plasma esterases [19]. Remifentanil does cross the placenta, but, unlike other opioids, appears to be rapidly metabolized and redistributed in the fetus leaving the smaller possibility of unwanted consequences (mainly neonatal respiratory depression, muscle rigidity, low Apgar and neurobehavioral scores) [19-21].

In the present study we investigated the effects of two remifentanil dosing regimens on intubating conditions and maternal blood pressure and heart rate response to the intubation in attempt to find the most effective remifentanil dose that would not adversely affect neonatal outcome.

\section{Material and Methods}

The study was approved by the local ethics committee. Seventy-seven ASA physical status I-II women with singleton term pregnancy, who were scheduled for elective caesarean section in general anesthesia and have given written informed consent, were enrolled in this prospective, randomized controlled study. Exclusion criteria were known cardiac, respiratory, neurologic, renal, endocrine, psychiatric disorders, history of drug or alcohol abuse, morbid obesity, preeclampsia, predicted difficult airway management (Mallampati score $>2$ a), active labor, known fetal congenital abnormalities or signs of fetal compromise. All patients refused regional anesthesia, or had absolute/relative medical contraindications to regional anesthesia.

In the operating room patients were placed supine with left uterine displacement, standard monitoring (noninvasive blood pressure, electrocardiography, pulse oximetry, capnography - using bedside monitor, model
BSM-2301k, Nihon Kohden Corporation, Tokyo, Japan and bispectral index - BIS electroencephalogram, using BIS-Vista monitoring system Norwood, Massachusetts, USA) was initiated and two intravenous lines established, one for remifentanil infusion (using Perfusor fm B/Brown, Melsungen AG, Germany), the other for the administration of other medications and fluids.

Patients were randomly allocated (using envelope method) to one of the following groups:

1. group (A) - 31 patient received $1 \mu \mathrm{g} / \mathrm{kg}$ remifentanil bolus, given over $30 \mathrm{~s}$, before the induction of anesthesia, followed by $0.15 \mu \mathrm{g} / \mathrm{kg} / \mathrm{min}$ remifentanil infusion that was stopped after the skin incision.

2. group (B) -27 patients received $1 \mu \mathrm{g} / \mathrm{kg}$ remifentanil bolus, given over $30 \mathrm{~s}$, just before the induction of anesthesia

3. control group (C) - 19 patients did not receive remifentanil until the delivery

After 3 minutes of preoxygenation through a facemask and remifentanil administration in A and B group, anesthesia was induced with thiopentone, starting with $3 \mathrm{mg} / \mathrm{kg}$ over $20 \mathrm{~s}$, followed by additional boluses (if needed) of $25 \mathrm{mg}$ until adequate dept of anesthesia has been reached (BIS values under 60, but not below 40); succinylcholine $1.5 \mathrm{mg} / \mathrm{kg}$ was administered and after $60 \mathrm{~s}$ endotracheal intubation was performed by the anesthetist blinded to group assignment, who also estimated and graded intubating conditions as excellent, good or poor (Table 1). The intubating score was evaluated according to the consensus conference on Good Clinical Research Practice in Pharmacodynamic Studies of Neuromuscular Blocking Agents [22]. Anesthesia was maintained with $1-1.5 \%$ end-tidal sevoflurane and $50 \%$ nitrous oxide in oxygen. Further muscle relaxation has been provided with rocuronium $0.6 \mathrm{mg} / \mathrm{kg}$. The lungs were mechanically ventilated to maintain end-tidal $\mathrm{PCO}_{2}$ of 28-32 mmHg, with fresh gas flow of $61 / \mathrm{min}$.

Beginning from the induction of anesthesia until delivery SAP, DAP, MAP (systolic, diastolic, main arterial pressure respectively) and HR (heart rate), were measured and recorded at 2 minutes interval. We specially

Table 1 Scoring conditions for endotracheal intubation

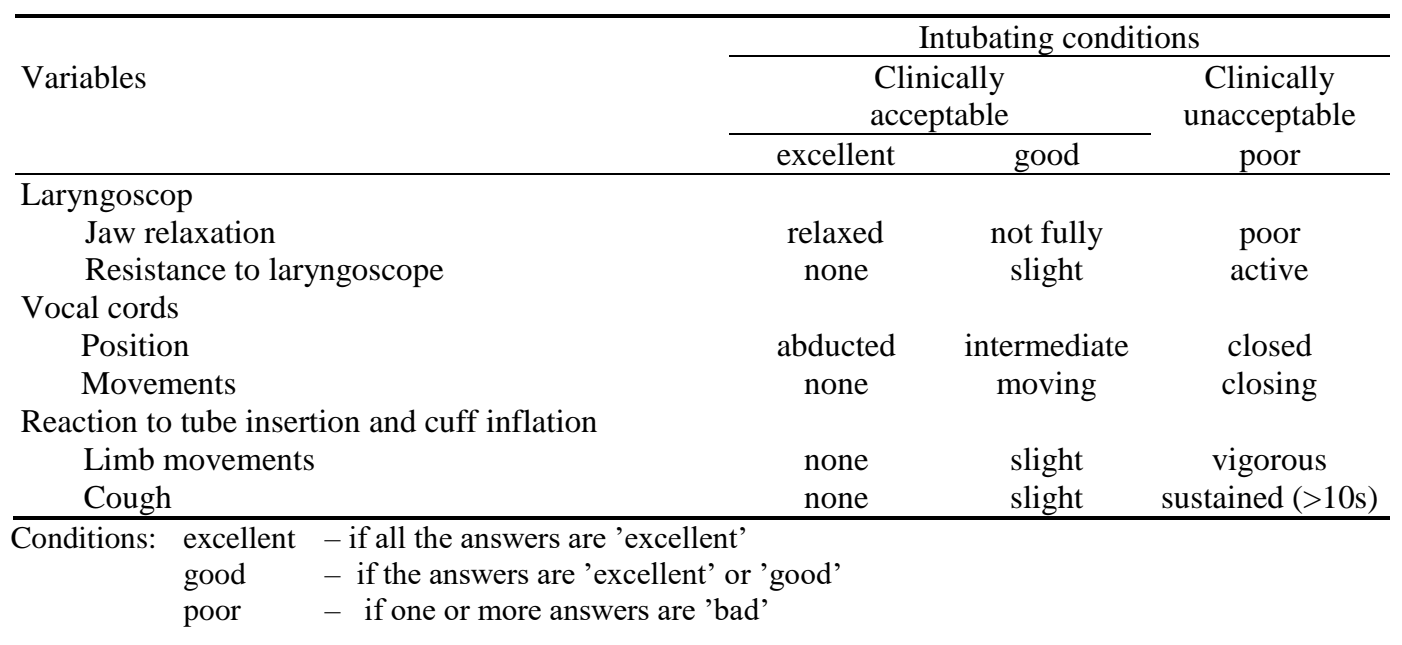


recorded values measured after induction to anesthesia (T1) and $30 \mathrm{~s}$ after endotracheal intubation (T2).

After delivery, pediatrician blinded to group assignment assessed the neonate and recorded the time to sustained respiration, Apgar score at $1^{\text {st }}$ and $5^{\text {th }}$ minute and resuscitative measures (if required), that might have included the use of tactile stimulation, beg-mask ventilation, endotracheal intubation or naloxone administration.

\section{Statistical analyses}

Statistical analysis was performed using SSPS statistic package, version 13. Normal distribution was evaluated with Kolmogorov-Smirnov test. Analysis of variance (ANOVA) was used for parameters comparison between three groups, with subsequent post hoc analysis. In cases of irregular data distribution Kruskal-Wallis test was utilized, with subsequent post hoc analysis with Mann-Whitney U test. The Chi-square test was used to verify the relation between categorical variables. The statistic hypothesis was tested on the significance level for risk of $\alpha=0.05$; the difference between samples was considered significant if $\mathrm{p}$ was $<0.05$.

\section{Results}

Seventy seven ASA status I-II parturients were included in this study. Patient's characteristics and surgical details are summarized in Table 2; no differences between groups have been observed.
Hemodynamic variables measured after the induction to anesthesia did not show statistical difference between groups (Table 3). After the intubation all hemodynamic variables in group $\mathrm{C}$ have raised significantly compared to groups A and B. The increase in variables was also greater in group B compared to A, but the difference did not reach statistical significance (Table 3)

The intubation conditions were excellent in 61 parturient $(79.2 \%)$, good in $15(19.5 \%)$ and poor in one parturient (1.3\%) (Graph 1).

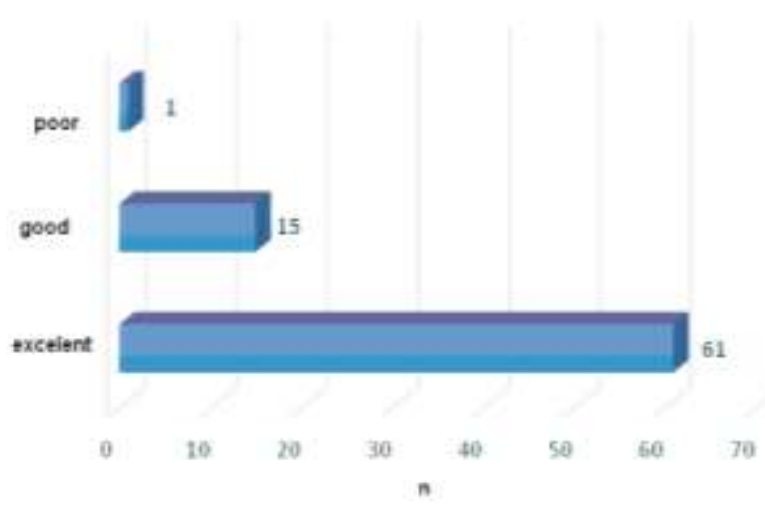

Graph 1 Intubation condition in our patients

The intubation scores showed significant difference between groups (Table 4.)

Table 2 Parturients characteristics and surgical details

\begin{tabular}{lccccc}
\hline & \multicolumn{3}{c}{ Group } & \multirow{2}{*}{ F } & p \\
\cline { 2 - 4 } & A & B & C & & 0.818 \\
\hline Age (years) & $31.74 \pm 4.46$ & $31.22 \pm 5.22$ & $30.89 \pm 1.04$ & 0.202 & 0.818 \\
Gestation weeks & $38.94 \pm 0.72$ & $39.04 \pm 1.09$ & $39.47 \pm 0.90$ & 2.162 & 0.122 \\
Weight (kg) & $77.19 \pm 13.27$ & $82.37 \pm 9.52$ & $79.26 \pm 11.84$ & 2.216 & 0.918 \\
I-D interval (minutes) & $11.22 \pm 1.67$ & $10.04 \pm 1.81$ & $10.37 \pm 1.71$ & 3.639 & 0.031 \\
U-D interval (seconds) & $57.39 \pm 18.93$ & $58.00 \pm 14.92$ & $60.42 \pm 22.25$ & 0.165 & 0.848 \\
\hline
\end{tabular}

F-ANOVA

Table 3 Hemodynamic variables after the induction to anesthesia (T1) and $30 \mathrm{~s}$ after the intubation (T2)

\begin{tabular}{|c|c|c|c|c|c|c|c|c|}
\hline \multirow[b]{3}{*}{ AP1 } & \multicolumn{5}{|c|}{$\mathrm{T}_{1}$} & \multirow{2}{*}{$\mathrm{F}$} & \multirow{2}{*}{$\mathrm{p}$} & \multirow{2}{*}{$\begin{array}{l}\text { Post } \\
\text { Hoc }\end{array}$} \\
\hline & & $\mathrm{A}$ & & $\mathrm{B}$ & $\mathrm{C}$ & & & \\
\hline & 110.03 & \pm 14.16 & 107.14 & \pm 12.59 & $116.89 \pm 9.93$ & 3.364 & 0.040 & $\mathrm{c}$ \\
\hline SAP2 & 119.61 & \pm 13.95 & 121.89 & \pm 13.82 & $149.00 \pm 14.50$ & 29.302 & $<0.001$ & $\mathrm{~b}, \mathrm{c}$ \\
\hline DAP1 & 67.93 & \pm 10.99 & 71.28 & \pm 10.51 & $75.31 \pm 14.60$ & 2.313 & 0.106 & \\
\hline DAP2 & 75.71 & \pm 12.93 & 81.56 & \pm 10.65 & $98.21 \pm 15.01$ & 18.750 & $<0.001$ & $\mathrm{~b}, \mathrm{c}$ \\
\hline MAP1 & 85.80 & \pm 13.21 & 84.22 & \pm 13.01 & $91.05 \pm 13.17$ & 1.590 & 0.211 & \\
\hline MAP2 & 91.06 & \pm 12.60 & 96.70 & \pm 12.49 & $116.68 \pm 14.76$ & 23.292 & $<0.001$ & $\mathrm{~b}, \mathrm{c}$ \\
\hline HR1 & 97.06 & \pm 9.88 & 94.70 & \pm 9.96 & $103.15 \pm 11.64$ & 3.819 & 0.026 & $\mathrm{c}$ \\
\hline HR2 & 100.68 & \pm 8.92 & 102.41 & \pm 11.02 & $109.68 \pm 9.61$ & 5.165 & 0.008 & $\mathrm{~b}, \mathrm{c}$ \\
\hline
\end{tabular}

F-ANOVA,

a (A vs B), b (A vs C), c (B vs C)

Abbreviations: SAP1 - systolic arterial pressure after the induction to anesthesia (mm Hg), SAP2 - systolic arterial pressure after the endotracheal intubation, DAP1 - diastolic arterial pressure after the induction to anesthesia (mm Hg), DAP2 - diastolic arterial pressure after the endotracheal intubation ( $\mathrm{mm} \mathrm{Hg}$ ), MAP1 - main arterial pressure after the induction to anesthesia (mm $\mathrm{Hg}$ ), MAP2 - main arterial pressure after the endotracheal intubation ( $\mathrm{mm} \mathrm{Hg}$ ), HR1 - heart rate after the induction to anesthesia (beat per minute), HR2 - heart rate after the induction to anesthesia (beat per minute) 
Table 4 Intubation conditions

\begin{tabular}{lrrrrr}
\hline Score (in \% of patients) & \multicolumn{3}{c}{ Group } & \multirow{2}{*}{$\chi^{2}$} & p \\
\cline { 2 - 4 } & \multicolumn{1}{c}{ A } & \multicolumn{1}{c}{ B } & \multicolumn{1}{c}{ C $n n n$} \\
\hline Poor & 0.0 & 0.0 & 5.3 & & \\
Good & 6.5 & 18.5 & 42.1 & 13.276 & 0.010 \\
excellent & 93.5 & 81.5 & 52.6 & & \\
\hline$\chi^{2}-$ chi square test & & & &
\end{tabular}

Table 5 Newborns characteristics

\begin{tabular}{|c|c|c|c|c|c|c|}
\hline & & \multicolumn{3}{|c|}{ Group } & \multirow{2}{*}{$\chi_{K W}{ }^{2} / F$} & \multirow[t]{2}{*}{$\mathrm{p}$} \\
\hline & & A & $\mathrm{B}$ & $\mathrm{C}$ & & \\
\hline $\mathrm{Ap}^{1}$ & & $8.81 \pm 0.55$ & $8.81 \pm 0.48$ & $8.63 \pm 0.49$ & 2.969 & 0.227 \\
\hline $\mathrm{Ap}^{5}$ & & $9.03 \pm 0.31$ & $8.93 \pm 0.26$ & $8.89 \pm 0.32$ & 2.972 & 0.226 \\
\hline Breathing* & immediately & 77.4 & 81.4 & 73.7 & & \\
\hline \multirow[t]{2}{*}{ (\% of newborns) } & tactile stimulation & 12.9 & 7.4 & 15.8 & & \\
\hline & bag mask ventilation & 9.7 & 11.1 & 10.5 & $4.365^{*}$ & 0.359 \\
\hline
\end{tabular}

F-ANOVA

$\chi_{\mathrm{KW}}{ }^{2}-$ Kruskal-Wallis test

Abbreviation: Ap ${ }^{1}-$ Apgar score in $1^{\text {st }}$ minute, $A p^{5}-$ Apgar score in $5^{\text {th }}$ minute

The greater percent of patients in group A had excellent sore $\left(\chi^{2}=6.471 ; \mathrm{p}=0.011\right)$, while in group $\mathrm{C}$ $42.1 \%$ of patients had good score $\left(\chi^{2}=5.617 ; \mathrm{p}=0.017\right)$. Patients with good score in group A (two patients) had intermediate vocal cords position and moving. All patients with good score in group B (five patients) had intermediate vocal cord position and moving; two of them $(7.4 \%)$ additionally had slight cough. All patients with good score in group $\mathrm{C}$ had intermediate vocal cord position; four of them $(21.2 \%)$ additionally had not fully relaxed jaw, one $(5.3 \%)$ slight cough. Patient with poor intubation score had poor jaw relaxation, vocal cords in closed position and slight limb movements.

Newborn characteristics are presented in Table 5, with no differences between groups in any of the estimated variables. All neonates were vital (Apgar score $\geq 8$ ). The reanimation of neonates who did not start to breathe immediately consisted only of brief (1-2 minutes) tactile stimulation or beg- mask ventilation.

\section{Discussion}

The number of studies reporting the use of remifentanil during I-D period of caesarean section is increasing. The dosing regiments were different and so were maternal effects and neonatal outcomes [13-15, 17, 18, 21, 23]. The suppression of exaggerated neuroendocrine response to endotracheal intubation and surgical stress was sometimes achieved at the expense of maternal hypotension or neonatal respiratory depression and lower first minute Apgar scores, so optimal remifentanil dosing regimen was yet to be determined.

In presented article we compared the effects of two remifentanil dosing regimens with remifentanil-free control, (meaning traditionally performed anesthesia, with omission of opioids during I-D interval), hypothesizing that remifentanil beneficial effects could justify its use. Group B received remifentanil bolus just before the induction to anesthesia. In group A remifentanil bolus was followed by infusion, meant to extent its analgesic effect to whole I-D period. The infusion was interrupted after skin incision; taking into account the average length of I-D period of caesarean section performed at our Clinic (10-11 min) and remifentanil context sensitive half-time of $3 \mathrm{~min}$, we believed this should leave enough time for remifentanil redistribution and metabolism in fetal circulation, thus diminishing the probability of neonatal respiratory depression.

According to our results both remifentanil dosing regimens successfully blunted maternal hemodynamic response to endotracheal intubation. SAP, DAP, MAP and $\mathrm{HR}$, measured $30 \mathrm{~s}$ after the intubation, were significantly higher in group $\mathrm{C}$ than in groups $\mathrm{A}$ and $\mathrm{B}$. The elevation of blood pressure after endotracheal intubation was even less in group A than in group B, but at this point of the operation the difference did not reach statistical significance (this will be reached as soon as at skin incision, but further analysis of maternal hemodynamic was beyond the scope of this article).

Intubating conditions (Table 5) in group A were also significantly better than in other groups. The excellent conditions were noted in $93.5 \%$ patients, compared to $81.5 \%$ in group B and $52.6 \%$ in group C; the difference between groups B and $\mathrm{C}$ was significant as well.

This finding did not come as a surprise, because it is known that remifentanil, used with propofol or thiopentone to facilitate endotracheal intubation, is an acceptable alternative to neuromuscular blocking drugs, since it may potentiate depression of the laryngeal reflexes [24]. Remifentanil boluses of $2-4 \mu \mathrm{g} / \mathrm{kg}$ (depending on a study) with propofol $2 \mathrm{mg} / \mathrm{kg}$ or thiopentone $5 \mathrm{mg} / \mathrm{kg}$, provided satisfactory or excellent intubating conditions [25-28]. Remifentanil-hypnotics synergism could be particularly useful in cases in which muscle relaxants are contraindicated, e.g. myopathies or choline-esterase enzyme deficiency [28]. Alexander et 
al. [29] reported successful use of $0.5 \mu \mathrm{g} / \mathrm{kg}$ remifentanil followed by $0.25 \mu \mathrm{g} / \mathrm{kg} / \mathrm{min}$, together with thiopentone for endotracheal intubation in a parturient with suxamethonium apnea.

Even when used with muscle relaxants, as in our study, remifentanil could be of great help in ameliorating intubating conditions, especially in cases where difficult intubation is anticipated. Due to physiologic changes of pregnancy, like airway edema, enlarged breasts, weight gain, change in Mallampati score, the risk of difficult/failed intubation is increased $[1,3]$. The incidence of difficult and failed intubation in obstetric patients is $1-6 \%$ and $0.13-0.6 \%$ respectively $(0.13-0.3 \%$ in general surgical population); additionally, the tolerance to apnea is reduced as a consequence of reduced pulmonal functional residual capacity and increased metabolic rate and oxygen consumption. This could lead to respiratory complications, like coughing, bucking, laryngospasm and bronchospasm, hypercarbia and hypoxia $[1,7,10]$, making airway management problems one of the leading causes of anesthesia-related maternal mortality [2]. According to our results, the addition of remifentanil will help provide smooth endotracheal intubation, ameliorate intubation conditions and attenuate excessive hemodynamic response. This effect could be particularly bene-

\section{References}

1. Rollins M, Lucero J. Overview of anesthetic considerations for Caesarean delivery. Br Med Bull 2012; 101:105-125.

2. Littleford J. Effects on the fetus and newborn of maternal analgesia and anesthesia: a review. Can J Anesth 2004; 51:586-609.

3. Mostić-Ilić T, Petronijević M, Antonijević V, Ivanković Ž, Mostić D, Kendrišić M. General anesthesia and uteroplacental drug transfer. Serbian J Anesth Intensive Therapy 2013; 35:381-5. http://www.uais.rs/wp-content/uploads/2013/12/ SJAITvol-35-7-8.pdf.

4. Khan MF, Samad K, Shamim F, Ullah H. Awareness during anesthesia-an update. Middle East J Anaesthesiol 2008; 19:723-735.

5. Paech MJ, Scott KL, Clavisi O, Chua S, McDonnell N. A prospective study of awareness and recall associated with general anaesthesia for caesarean section. Int J Obstet Anesth 2009; 17:298-303.

6. Dünges B, Heid F, Dauster M, Strecker U, Röhrig B, Brambrink AM. Revisited: Haemodynamic instability and endocrine response during endotracheal tube-placement. A prospective, randomized trial using topical lidocaine and a lightwand. Open Anesthesiol J 2008; 2:30-39. doi:10.2174/ 1874321800802010030

7. Hagberg C, Georgi R, Krier C. Complications of managing the airway. Best Pract Res Clin Anaesthesiol. 2005;19:641-659.

8. Lin SY, Hu CJ, Lin HC. Increased risk of stroke in patients who undergo cesarean section delivery: a nationwide population-based study. Am J Obstet Gynecol 2008; 98:e1-7.

9. Jadon A. Complications of regional and general anaesthesia in obstetrics practice. Indian J Anest. 2010; 54:415-420.

10. Brown JPR. Recent developments in anaesthesia for caesarean section in the UK. Update Anaesth 2008; 23:3-7.

11. Kutlesic MS, Kutlesic RM, Mostic-Ilic T. Attenuation of cardiovascular stress response to endotracheal intubation by the use of remifentanil in patients undergoing caesarean delivery. $\mathbf{J}$ Anesth 2016; 30(2):274-283.

12. Khan FA, Ullah H. Pharmacological agents for preventing morbidity associated with the haemodynamic response to ficial in parturients with serious comorbidities, e.g. preeclampsia, but also in healthy obstetric population.

Opposite to the data from the literature $[15,17,18$, 21,23 , remifentanil regimens applied in our study did not affect neonatal outcome. First minute Apgar scores were $\geq 8$ in all cases, without difference between groups. Majority of neonates (77.4\% in group A, $81.4 \%$ in group $\mathrm{B}, 73.7 \%$ in group C) started breathing within few seconds after delivery. Resuscitative measures applied to the neonates with respiratory depression consisted of tactile stimulation and brief beg-mask ventilation with no significant difference between groups. There was no need for endotracheal intubation or for naloxone administration, and no muscular rigidity was observed.

\section{Conclusion}

Our dosing regimen of remifentanil $1 \mu \mathrm{g} / \mathrm{kg}$ bolus given immediately before the induction followed by $0.15 \mu \mathrm{g} / \mathrm{kg} / \mathrm{min}$ interrupted after skin incision provided the best compromise between achievement of excellent intubating conditions, attenuation of maternal blood pressure and heart rate response to endotracheal intubation, and avoidance of neonatal respiratory depression. tracheal intubation. Cochrane Database Syst Rev. 2013; 7:CD004087. doi:10.1002/14651858.CD004087.pub2.

13. Hessen M, Klohr S, Hofmann T, Rossiant R, Devroe S, Straube $S$, Van de Velde M. Maternal and foetal effects of remifentanil for general anaesthesia in parturients undergouing caesarean section: a systematic review and meta-analysis. Acta Anesthesiol Scand 2013; 57:29-36.

14. Hill D. The use of remifentanil in obstetrics. Anesthesiol Clin. 2008; 26(1):169-182.

15. Yoo KY, Jeong CW, Park BY, Kim SJ, Jeong ST, Shin MH, Lee J. Effects of remifentanil on cardiovascular and bispectral index responses to endotracheal intubation in severe pre-eclamptic patients undergoing Caesarean delivery under general anaesthesia. Br J Anaesth 2009; 102:812-819. doi:10.1093/bja/aep099

16. Egan TD, Kern SE, Muir KT, White J. Remifentanil by bolus injection: a safety, pharmacokinetic, pharmacodynamic and age effect investigation in human volunteers. Br J Anaesth 2004; 92:335-343.

17. Draisci G, Valente A, Suppa E, Frassanito L, Pinto R, Meo F, De Sole $\mathrm{P}$, Bossù E, Zanfini BA. Remifentanil for cesarean section under general anesthesia: effects on maternal stress hormone secretion and neonatal well-being: a randomized trial. Int $\mathrm{J}$ Obstet Anesth 2008; 17:130-136. doi:10.1016/j.ijoa.2008.01.002.

18. Kee WDN, Kaw KS, Ma KC, Wong ASY, Lee BB, Floria F. Maternal and neonatal effects of remifentanil at induction of general anesthesia for cesarean delivery. Anesthesiology 2006; 104:14-20.

19. Glass PSA, Gan TJ, Howell S. A review of the pharmacokinetics and pharmacodynamics of remifentanil. Anesth Analg 1999; 89:S7-14.

20. Kan RE, Hughes SC, Rosen MA, Kessin C, Preston PG, Lobo EP. Intravenous remifentanil: placental transfer, maternal and neonatal effects. Anesthesiology 1998; 88:1467-1474.

21. Van de Velde M, Teunkens A, Kuypers M, Dewinter T, Vandermeersch E. General anaesthesia with target controlled infusion of propofol for planned caesarean section: maternal and neonatal effects of a remifentanil-based technique. Int $\mathbf{J}$ Obstet Anesth 2004; 13:153-158. 
22. Viby-Mogensen J, Engbaek J, Ericson LI et al. Good Clinical Research Practice (GCRP) in pharmacodynamic studies of neuromuscular blocking agents. Acta Anesth Scand 1996; 40:59-74.

23. Noskova P, Blaha J, Bakhouche H, Kubatova J, Ulrichova J, Marusicova P, Smisek J, Parizek A, Slanar O, Michalek P. Neonatal effect of remifentanil in general anaesthesia for caesarean section: a randomized trial. BMC Anesthesiol 2015; 15:38. doi:10.1186/s12871-015-0020-1.

24. Eyigor C, Cagiran E, Balcioglu T, Uyar M. Comparison of the effects of remifentanil and remifentanil plus lidocaine on intubation conditions in intellectually disabled patients. Braz $\mathrm{J}$ Anesthesiol 2014; 64(4):263-268. http://dx.doi.org/10.1016/j.bjane.2013. 03.006

25. Jeon YT, Oh AY, Park SH, Hwang JW, Park HP. Optimal remifentanil dose for lightwand intubation without muscle relaxants in healthy patients with thiopental coadministration: a prospective randomized study. Eur J Anaesthesiol 2012; 29(11):520-523.

26. Durmus M, Ender G, Kadir BA, Nurcin G, Erdogan O, Ersoy MO. Remifentanil with thiopental for tracheal intubation without muscle relaxants. Anesth Analg 2003; 96(5):1336-1339.

27. Erhan E, Ugur G, Gunusen I, Alper I, Oyzar B. Propofol- not thiopental or etomidate - with remifentanil provides adequate intubating conditions in the absence of neuromuscular blocade. Can J Anaesth 2003; 50(2):108-115.

28. Imani F, Alebouyeh MR, Amvari ZT, Faiz SHR.Use of remifentanil and alfentanil in endotracheal intubation: a comparative study. Anesth Pain Med 2011; 1(2):61-65.

29. Alexander R, Fardell S. Use of remifentanil for tracheal intubation for caesarean section in a patient with suxamethonium apnoea. Anaesthesia 2005; 60:1036-1038. 